\title{
On The Number of Top Sport Teams in a Town
}

\begin{abstract}
By Seppo Suominen
Top teams in sports typically are located in large towns since the junior teams of a top team have a bigger number of talents available and a large proportion of top players come from own junior team. This is especially true in women sport. A large town is able to support a large number of fans and visitors to a game, which results in higher ticket revenue. A large majority on the location of top teams uses male sports and there is no evidence concerning whether female sports follows the same structure. Is it so that if there is a top team of men located in a town, there is also a top women team? Are there any differences across genders in the location? The aim of this study is to include women sport and compare income elasticity of men sport and women sport. The variable to be explained is the cumulative amount of top teams located in a town. Top teams in this setting means that the team is playing in the highest league. Six different sports are included: ice hockey, football, (Finnish style) baseball, floorball, basketball and volleyball. The data covers 28 seasons from 1990 (or 1990/91) to 2017 (or 2017/2018). The Poisson regression and negative binomial regression results show that the cumulative number of male sport teams is positively related to population and negatively to average incomes. The negative income elasticity is weaker in the case of women sports. The coefficient is not significant in negative binomial regression model. Some prescriptive analysis concerning location correlation and autocorrelation is also given.
\end{abstract}

Keywords: Top Sport Teams, Finland, Location, Poisson and Negative Binomial Estimation.

\section{Introduction and Motivation}

Based on long run statistics (Itkonen and Nevala 1998) top teams in sports typically are located in large towns since the junior teams of a top team have a bigger number of talents available and a large proportion of top players come from own junior. This is especially true in women sport. A large town is able to support a large number of fans and visitors to a game which results in higher ticket revenue. The definition town here refers to an area where customers are able to choose different goods and visit different evens without restrictions from travel costs or travel time. However, there are some studies showing that the income elasticity of a game is negative indicating that high-income towns are not able to support a same amount of top teams than otherwise equal town with lower average income level of the citizens (Borland and Lye 1992, Baimbridge et al. 1996, Falter and Perignon 2000). However, there are studies showing a positive income elasticity (Depken 2001, Coates and Harrison 2005, Coates abd Humphreys 2007), thus the result concerning income elasticity is mixed and might be explained with the particular sports and country in the

"Senior Lecturer, Haaga-Helia University of Applied Sciences, Finland. 
study. A large majority on the location of top teams uses male sports and there is no evidence concerning whether female sports follows the same structure. There is not enough evidence concerning the situation with women sports. Is it so that if there is a top team of men located in a town, there is also a top women team? Are there any differences across genders in the location?

The aim of this study is get more information concerning average income sensitivity using a long data set of top teams in Finland. The study is an extended repetition to a recent study of the author (Suominen 2017) where it was shown that in Finland the cumulative amount of top men teams over a 26 year period is positively related to population statistics of the town but negatively to incomes of citizens in the town. The aim of this study is to include women sport and compare income elasticity of men sport and women sport. The variable to be explained is the cumulative amount of top teams located in a town. Top teams in this setting means that the team is playing in the highest league. In each year the best of these teams is the Finnish champion. Six different sports are included: ice hockey, football, (Finnish style) baseball, floorball, basketball and volleyball. The data covers 28 seasons from 1990 (or 1990/91) to 2017 (or 2017/2018).

\section{Related Literature}

In the National Hockey League the teams are given franchise by the national league organisation. The main arguments of the franchise survival are population and location (Jones and Ferguson 1988). In the 1970's there were 16 teams in the NHL. During that time the league did not have a national US television contract and the teams did not have any ticket revenue sharing system. The location of the team was therefore very important for generating revenue. Quirk and El Hodiri (1974) showed that the greater the revenue processing ability of the team's location, the greater is the team's talent stock. The team is able to increase playing skills through acquiring top players if financial resources are adequate. Teams use more financial resources on talents if the league is open meaning that the weakest is subject to relegation than they do in closed, franchise system leagues (Ross and Szymanski 2002). The location is vital for generating revenues. However, (Coates and Humphreys 1999) show that sport stadia construction and economic climate of the area are negatively correlated. If the town receives a new sports franchise and as a result of that there is stadia construction, the impact on incomes of the town is negative. Moreover, (Siegfried and Zimbalist 2000, Siegfried and Zimbalist 2006) show that the argument of subsidising sports arena with tax revenue in order to generate economic benefits to the town is not valid. Sport facilities will not stimulate municipal economies.

Oberhofer et al. (2015) show following Quirk and El Hodiri (1974) that revenue generation or financial resources are vital for survival in the highest league in German football but the local market size measured by population has a low negative effect on survival. A team's relegation is positively related 
to low budget, past performance and age. The author of this study (Suominen 2017) has shown that in men sport the cumulative number of teams playing in the highest league over a 26-year period is positively related to town population but negatively to town average incomes indicating that the demand for team sport has a negative income elasticity. The data included Finnish ice hockey, football, floorball, (Finnish style) baseball, volleyball and basketball.

Income elasticity is positive in consuming sport. Using 13 different sports activities (Thibaut et al. 2017) show that exercising sports has a positive income elasticity. In general male sports participants and those with higher levels of education spend more time and money on sports while the effect of age and urbanisation is not so clear. The determinants of time spent on sports participation and sports expenditure have in general similar signs but this is not evident for household or personal incomes. If money spent on active sports participation or exercising sports has a positive correlation with money spent on watching sports in a spectators' hall, then the income elasticity should be positive for the demand for team sports. However, the many results propose that this is not the case. (Downward and Rasciute 2010) show that a higher income increases the ratio of exercising sports to leisure activities (like music listening, going to cinema or visiting museums). High income persons seem to increase exercising sports in the cost of other leisure activities. There are substantial differences across nations in exercising sports and watching sports as (Hartmann-Tews 2006) and the author of this study (Suominen 2017) have shown. The cultural dimensions as defined by (Hofstede 1980) are important.

\section{A Model}

A simple oligopoly model is suitable for analysing the number of top teams in a town. With the help of the model, the number of top teams in the long run is solved. The model assumes that different sports are perfect substitutes from the viewpoint of spectators, which is not a plausible assumption. However, the model is a method to receive theoretical results concerning the number of teams that a town can sustain. Since the weakest teams are subject to relegation and there is some variation in the location of the top teams during a long period, the long run equilibrium number of teams must be analysed. Following (Martin 1993: 175) we have $n$ Cournot quantity setting firms in a market (town, region) with linear inverse demand curve.

(1) $p=a-b Q, Q=q_{1}+q_{2}+\cdots+q_{n}$

where $q_{i}$ denotes the number of spectators over the season. We assume that all sports are perfect substitutes. Each team produces with a quadratic cost function.

(2) $C(q)=F+c q+d q^{2}, c, d>0$ 
Marginal cost exceeds average costs since $d>0$ and there are diseconomies of scale. The average cost minimising level of output (the output for which marginal cost equal average costs) with this cost function is:

(3) $q_{M E S}=\left(\frac{F}{d}\right)^{1 / 2}$

Minimum efficient scale as a fraction of the market size $M=\frac{a-c}{b}$ is

(4) $M E S=\frac{q_{M E S}}{M}=\frac{\left(\frac{F}{d}\right)^{1 / 2}}{M}$

In the short run the number of firms $n$ is exogenously determined and based on previous success in the league. The worst teams are subject to relegation while the better teams continue in the top (higher league). Solving the first order conditions of profit maximisation and assuming that all firms are identical, the Cournot equilibrium output of each team is:

(5) $q=\frac{M}{n+1+2\left(\frac{d}{b}\right)}$

The total number of spectators, $\mathrm{Q}$ are price, $\mathrm{p}$ are:

(6) $Q=\frac{n}{n+1+2\left(\frac{d}{b}\right)} M p=c+\frac{1+\frac{d}{b}}{n+1+2\left(\frac{d}{b}\right)} b M$

In the long run we assume that the number of teams, $n$ adjusts so that each team earns zero profit:

(7) $\pi=b\left(1+\frac{d}{b}\right)\left(\frac{M}{n+1+2\left(\frac{d}{b}\right)}\right)^{2}-F=0$

We can solve (7) and the number of teams in the long run, $n_{L R}$ :

(8) $n_{L R}=\frac{M}{\left(\frac{F}{b+d}\right)^{1 / 2}}-\left(1+2 \frac{d}{b}\right)=\frac{1}{M E S}-\left(1+2 \frac{d}{b}\right)$

In the long run, the number of teams, $n_{L R}$ is greater, the smaller is the fixed cost, $F$, or the smaller is the minimum efficient scale output as a fraction of market size. The model also proposes that the number of top teams in the 
town is positively related to the market size (M). The model assumes that all sports are perfect substitutes but empirical data is not in line with the assumption. Therefore, the result above is just a rough theoretical model of the number of top teams in a town.

\section{Data and Descriptive Analysis}

Some descriptive analysis is first presented in Table 1 . In one season the number of teams in the highest league varies from 6 to 16. In average the women leagues have had a lower number of teams playing regular season games. For example the overall number of female teams in ice hockey has been 215 ( 7.67 per season) and the corresponding figure for male teams is 370 (13.21 per season). But the variation of home towns is higher for women ice hockey. During the period 1990/91 to 2017/28 the number of different towns is 21 for women ice hockey while highest league ice hockey men teams have been located in 16 towns. The same is true with football, volleyball and baseball: more variation in the location of women teams while the opposite is seen in floorball or basketball. In these there is more variation in the location with men than with women.

Top female baseball teams have been located in 30 different towns during the 28 seasons which is the largest figure indicating that there has been a largest variation across different sports. Male baseball league on average has had more teams than female baseball and the number of different towns is lower (men 28, women 30). If autocorrelation statistics is used to stand for variation the above is verified. Women baseball and volleyball are geographically more spread. The base year in the autocorrelation statistics below is year 2003 (Table 2). If the location of top teams is the same in two seasons then autocorrelation statistics is one. A high autocorrelation means across years in relation to base year 2003 means that there is small variation between locations.

As shown in Table 2, the weakest team typically is relegated to a lower division or league therefore for example the correlation coefficient of female ice hockey in 2004 (vs. 2003) is 0.882 indicating that almost the same towns have a top team and almost the same towns do not have a top team during these two sequential seasons. If only female sports is observed approximately the lowest correlation coefficients can be found in baseball and volleyball. In baseball the autocorrelation coefficient is less than 0.50015 times. In volleyball the same figure is $8(8 / 28)$. Floorball and basketball have been geographically more stable based in autocorrelation coefficients. 
Table 1. Descriptive Analysis

\begin{tabular}{|c|c|c|c|c|c|c|c|c|c|c|c|c|}
\hline & IC, W & $\mathrm{IC}, \mathrm{M}$ & $\mathrm{FB}, \mathrm{W}$ & $\mathrm{FB}, \mathrm{M}$ & $\mathrm{BA}, \mathrm{W}$ & BA, M & FL, W & FL, M & $\mathrm{VO}, \mathrm{W}$ & $\mathrm{VO}, \mathrm{M}$ & $\mathrm{BB}, \mathrm{W}$ & $\mathrm{BB}, \mathrm{M}$ \\
\hline Regular, \# & $6-9$ & $12-15$ & $10-12$ & $10-14$ & $10-12$ & $11-15$ & $10-12$ & $10-14$ & $7-11$ & $7-13$ & $8-11$ & $10-16$ \\
\hline Towns, \# & 21 & 16 & 24 & 23 & 30 & 28 & 22 & 24 & 28 & 25 & 19 & 21 \\
\hline All, \# & 215 & 370 & 286 & 350 & 322 & 365 & 321 & 356 & 255 & 304 & 260 & 344 \\
\hline
\end{tabular}

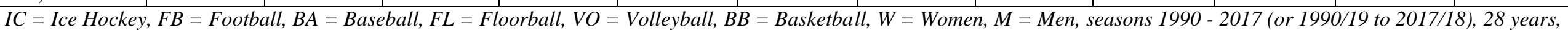

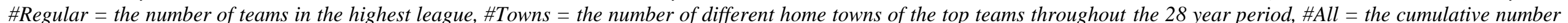
of top teams, note that it is possible the one team has alweays been in top. 
Table 2. Autocorrelation Coefficients of Home Town, The Base Year is 2003, Female Sports

\begin{tabular}{|l|c|c|c|c|c|c|}
\hline & IC, $w$ & FO, w & BA, w & FL, w & VO, w & BB, w \\
\hline 1990 & 0.306 & 0.634 & 0.259 & 0.58 & 0.236 & 0.56 \\
\hline 1991 & 0.306 & 0.528 & 0.259 & 0.611 & 0.346 & 0.742 \\
\hline 1992 & 0.306 & 0.606 & 0.259 & 0.574 & 0.236 & 0.742 \\
\hline 1993 & 0.496 & 0.707 & 0.358 & 0.645 & 0.346 & 0.787 \\
\hline 1994 & 0.433 & 0.808 & 0.358 & 0.661 & 0.428 & 0.787 \\
\hline 1995 & 0.559 & 0.687 & 0.457 & 0.665 & 0.553 & 0.858 \\
\hline 1996 & 0.559 & 0.687 & 0.358 & 0.661 & 0.709 & 0.845 \\
\hline 1997 & 0.72 & 0.687 & 0.358 & 0.772 & 0.553 & 0.768 \\
\hline 1998 & 0.833 & 0.687 & 0.457 & 0.752 & 0.665 & 0.845 \\
\hline 1999 & 0.858 & 0.656 & 0.556 & 0.705 & 0.709 & 0.922 \\
\hline 2000 & 0.899 & 0.705 & 0.556 & 0.604 & 0.776 & 0.877 \\
\hline 2001 & 0.858 & 0.813 & 0.655 & 0.774 & 0.888 & 0.835 \\
\hline 2002 & 0.96 & 0.899 & 0.852 & 0.917 & 0.943 & 0.877 \\
\hline 2003 & 1 & 1 & 1 & 1 & 1 & 1 \\
\hline 2004 & 0.882 & 0.941 & 0.733 & 0.894 & 0.776 & 0.919 \\
\hline 2005 & 0.939 & 0.941 & 0.794 & 0.81 & 0.776 & 0.835 \\
\hline 2006 & 0.939 & 0.803 & 0.691 & 0.803 & 0.776 & 0.837 \\
\hline 2007 & 0.804 & 0.877 & 0.691 & 0.721 & 0.826 & 0.784 \\
\hline 2008 & 0.739 & 0.762 & 0.691 & 0.752 & 0.709 & 0.53 \\
\hline 2009 & 0.559 & 0.669 & 0.754 & 0.639 & 0.76 & 0.427 \\
\hline 2010 & 0.522 & 0.532 & 0.691 & 0.752 & 0.637 & 0.632 \\
\hline 2011 & 0.604 & 0.564 & 0.626 & 0.752 & 0.637 & 0.632 \\
\hline 2012 & 0.559 & 0.483 & 0.486 & 0.681 & 0.637 & 0.699 \\
\hline 2013 & 0.559 & 0.363 & 0.358 & 0.506 & 0.592 & 0.686 \\
\hline 2014 & 0.559 & 0.402 & 0.383 & 0.611 & 0.441 & 0.645 \\
\hline 2015 & 0.559 & 0.564 & 0.486 & 0.54 & 0.519 & 0.528 \\
\hline 2016 & 0.433 & 0.437 & 0.486 & 0.572 & 0.441 & 0.667 \\
\hline 2017 & 0.575 & 0.483 & 0.589 & 0.477 & 0.358 & 0.667 \\
\hline & & & & & & \\
\hline
\end{tabular}


Table 3. Autocorrelation Coefficients of Home Town, the Base Year is 2003, Male Sports

\begin{tabular}{|c|c|c|c|c|c|c|}
\hline & IC & $\mathrm{FO}$ & $\mathrm{BA}$ & FL & $\mathrm{VO}$ & $\mathrm{BB}$ \\
\hline 1990 & 0.899 & 0.573 & 0.468 & 0.812 & 0.238 & 0.264 \\
\hline 1991 & 0.832 & 0.651 & 0.468 & 0.75 & 0.352 & 0.264 \\
\hline 1992 & 0.899 & 0.71 & 0.379 & 0.805 & 0.326 & 0.264 \\
\hline 1993 & 0.899 & 0.676 & 0.379 & 0.865 & 0.329 & 0.285 \\
\hline 1994 & 0.843 & 0.695 & 0.468 & 0.868 & 0.431 & 0.285 \\
\hline 1995 & 0.843 & 0.621 & 0.468 & 0.892 & 0.385 & 0.32 \\
\hline 1996 & 0.899 & 0.676 & 0.357 & 0.868 & 0.551 & 0.417 \\
\hline 1997 & 0.899 & 0.583 & 0.357 & 0.868 & 0.551 & 0.538 \\
\hline 1998 & 0.899 & 0.543 & 0.357 & 0.772 & 0.671 & 0.665 \\
\hline 1999 & 0.967 & 0.748 & 0.678 & 0.624 & 0.837 & 0.615 \\
\hline 2000 & 1 & 0.748 & 0.647 & 0.824 & 0.795 & 0.832 \\
\hline 2001 & 1 & 0.682 & 0.647 & 0.824 & 0.961 & 0.832 \\
\hline 2002 & 1 & 0.848 & 0.904 & 0.885 & 0.961 & 0.916 \\
\hline 2003 & 1 & 1 & 1 & 1 & 1 & 1 \\
\hline 2004 & 1 & 0.89 & 0.741 & 0.945 & 0.884 & 0.871 \\
\hline 2005 & 0.968 & 0.816 & 0.741 & 0.837 & 0.884 & 0.736 \\
\hline 2006 & 0.968 & 0.773 & 0.809 & 0.845 & 0.795 & 0.825 \\
\hline 2007 & 0.968 & 0.695 & 0.71 & 0.845 & 0.573 & 0.736 \\
\hline 2008 & 0.968 & 0.743 & 0.741 & 0.712 & 0.625 & 0.736 \\
\hline 2009 & 0.968 & 0.669 & 0.754 & 0.771 & 0.71 & 0.647 \\
\hline 2010 & 0.968 & 0.669 & 0.714 & 0.712 & 0.728 & 0.736 \\
\hline 2011 & 0.968 & 0.573 & 0.556 & 0.741 & 0.728 & 0.592 \\
\hline 2012 & 0.968 & 0.651 & 0.523 & 0.726 & 0.71 & 0.557 \\
\hline 2013 & 0.968 & 0.573 & 0.523 & 0.726 & 0.661 & 0.647 \\
\hline 2014 & 0.898 & 0.573 & 0.523 & 0.726 & 0.54 & 0.499 \\
\hline 2015 & 0.867 & 0.573 & 0.523 & 0.756 & 0.573 & 0.342 \\
\hline 2016 & 0.8 & 0.495 & 0.557 & 0.672 & 0.573 & 0.438 \\
\hline 2017 & 0.8 & 0.417 & 0.647 & 0.538 & 0.573 & 0.499 \\
\hline
\end{tabular}

Table 3 shows that male ice hockey has been the most stable in terms of home town. That be explained by the fact that ice hockey league has been closed. The weakest has not been relegated and some new teams have been given the top league position. Floorball and football are very close to ice hockey in the home town variation but these sports have never been closed. The variation of top basketball and baseball teams' location has been highest based on autocorrelation coefficients.

Table 4 presents the correlation coefficients of different sports location during the 2003 (or 2003/04) season. 
Table 4. Correlation Coefficients of Sports' Home Town during Season 2003

\begin{tabular}{|c|c|c|c|c|c|c|c|c|c|c|c|c|}
\hline & IC, W & FO, W & BA, W & FL, W & $\mathrm{VO}, \mathrm{W}$ & $\mathrm{BB}, \mathrm{W}$ & IC & FO & BA & FL & VO & BB \\
\hline IC, W & 1 & 0.522 & 0.131 & 0.573 & 0.145 & 0.311 & 0.707 & 0.193 & 0.013 & 0.728 & 0.193 & 0.295 \\
\hline $\mathrm{FO}, \mathrm{W}$ & & 1 & -0.089 & 0.514 & -0.003 & 0.604 & 0.537 & 0.310 & -0.018 & 0.663 & 0.109 & 0.108 \\
\hline BA, W & & & 1 & 0.150 & -0.015 & -0.101 & 0.370 & 0.044 & 0.160 & 0.046 & -0.043 & 0.036 \\
\hline FL, W & & & & 1 & 0.076 & 0.513 & 0.588 & 0.260 & -0.031 & 0.791 & 0.186 & 0.420 \\
\hline $\mathrm{VO}, \mathrm{W}$ & & & & & 1 & -0.096 & 0.140 & 0.151 & -0.025 & 0.135 & 0.059 & 0.245 \\
\hline $\mathrm{BB}, \mathrm{W}$ & & & & & & 1 & 0.401 & 0.354 & -0.107 & 0.500 & -0.027 & 0.284 \\
\hline IC & & & & & & & 1 & 0.509 & -0.049 & 0.677 & 0.087 & 0.304 \\
\hline FO & & & & & & & & 1 & 0.031 & 0.279 & 0.018 & 0.246 \\
\hline BA & & & & & & & & & 1 & -0.035 & -0.053 & -0.066 \\
\hline FL & & & & & & & & & & 1 & 0.151 & 0.285 \\
\hline VO & & & & & & & & & & & 1 & 0.087 \\
\hline BB & & & & & & & & & & & & 1 \\
\hline & & & & & & & & & & & & \\
\hline
\end{tabular}


The correlation matrix of season 2003 (2003/2004) reveals that male volleyball, basketball and baseball as well as female baseball and volleyball seem to have the lowest correlation coefficients with other sports. It shows that these sports are most separated. These are least played simultaneously in a same town with other sports on the top level. On the contrary, ice hockey and floorball, both female and male, seem to be played in the same towns where also top female football was played in 2003. It can be argued that the latter seem to cluster in rather large towns in Finland. The dendrogram of the cluster analysis (Figure 1) verifies the result of the average distances between sports. Male volleyball (vo2003) is the most separate in terms of location in 2003.

Figure 1. Dendrogram, Season 2003

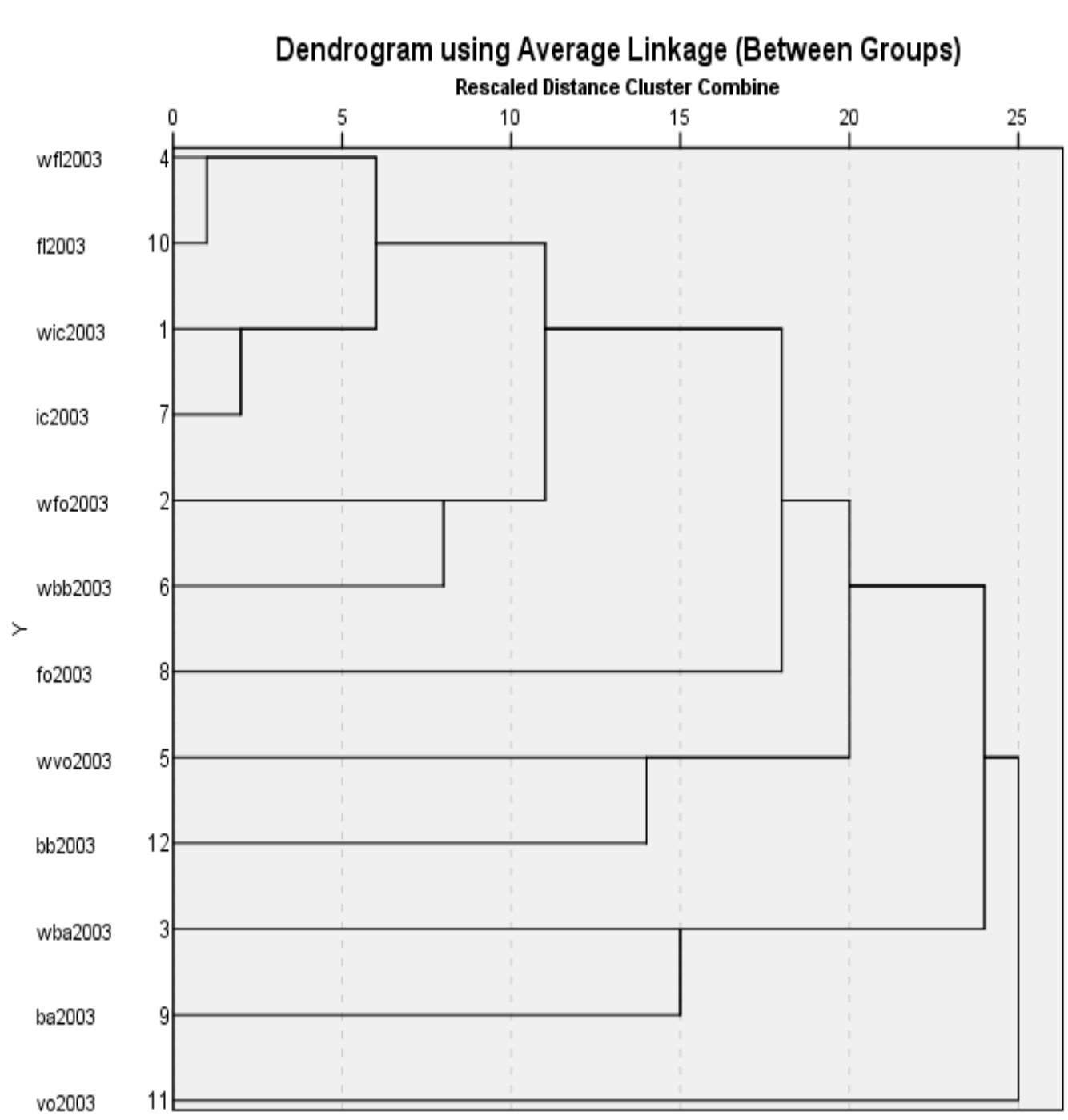




\section{Estimation and Results}

The oligopoly model above proposes that the number of teams in the long run and market size should be positively related. The cumulative number of teams over the years is negatively related with fixed costs of the team. A systematic cost analysis of the top teams has not been made with Finnish teams but based on newspaper articles it can be argued that female sports and only sports played in Finland, i.e. baseball (with Finnish rules) have lower fixed cost due to lower salaries we should see these sports in also smaller towns where the spectator number is smaller. Top Finnish ice hockey (football, volleyball, basketball) players have the option to get higher salaries in top professional leagues, like NHL or NBA. That leads to higher salaries in Finland that is the case with pure Finnish sports like Finnish rule baseball. Therefore we should observe that the variation of towns where baseball has been played throughout the history is higher. Table 1 reveals that baseball in top level has been played in a bigger number of towns than any other sports during the period from 1990 to 2017.

The output variable in the Poisson and Negative Binomial estimations is the cumulative number of teams in a town over a period from 1990 to 2017. In figure 2 the cumulative number is illustrated.

Figure 2. Cumulative Number of Teams, 1990 - 2017

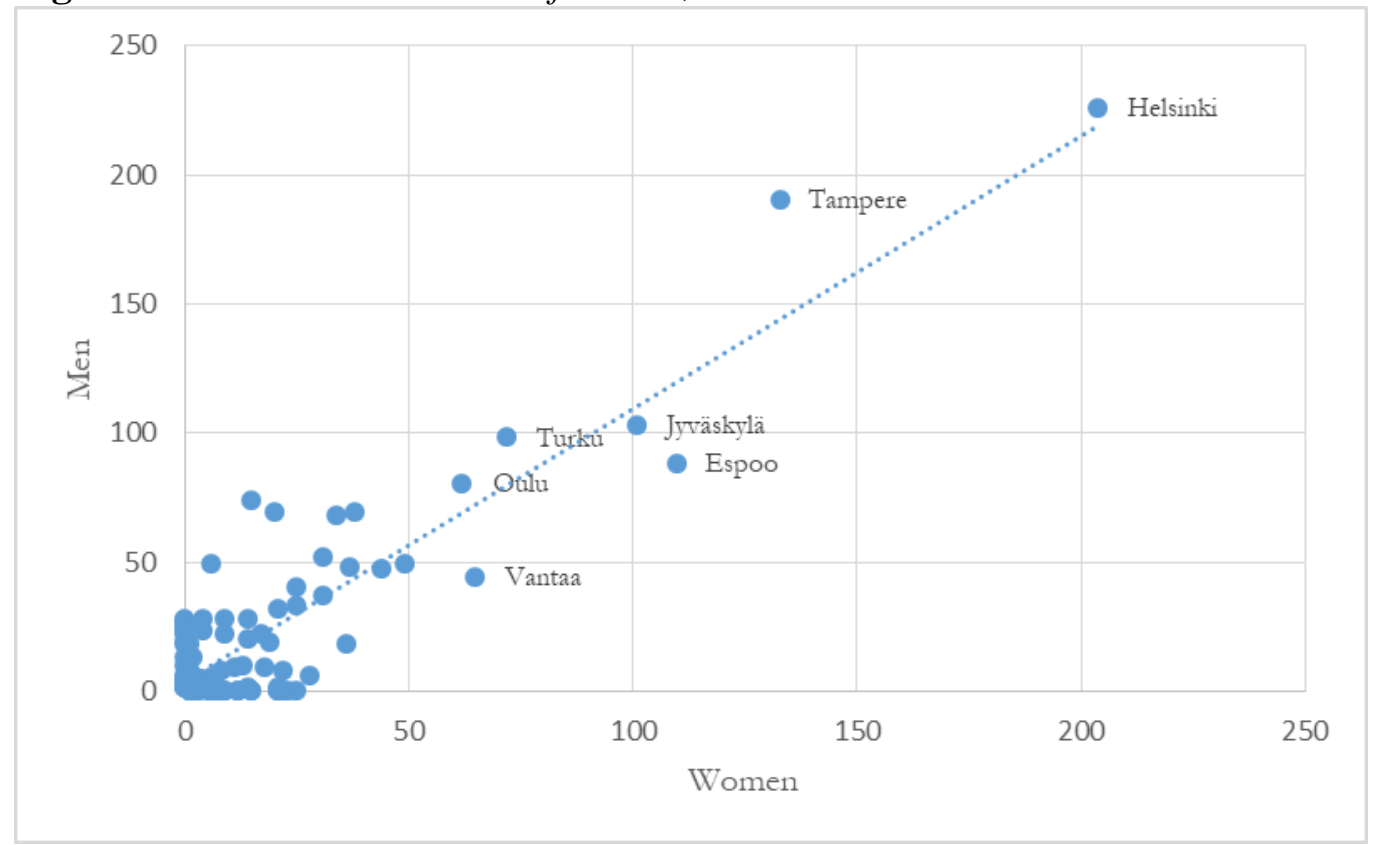

The cumulative number of male teams and female teams are correlated $(\mathrm{r}=$ 0.883 ). If the data is cut and only figures up to 50 are taken into account (in Figure 2 the lowest corner on the left) the correlation coefficient is 0.522 . Below the regression line in figure 2, there are three large towns: Jyväskylä, Espoo and Vantaa that seem to have had a larger amount of female top teams 
than an average large town. The population of Espoo and Vantaa are larger than that of Jyväskylä but they are neighbours of Helsinki which seems to have a negative impact on the cumulative number of teams of these two towns.

If the cumulative number of male teams is zero $(n=24)$, the cumulative number of female teams varies from 1 to 25 (Figure 3). The share of these observations in the whole sample (\# towns 92 ) is $26 \%$.

Figure 3. Cumulative Number of Female Teams if Male is Zero

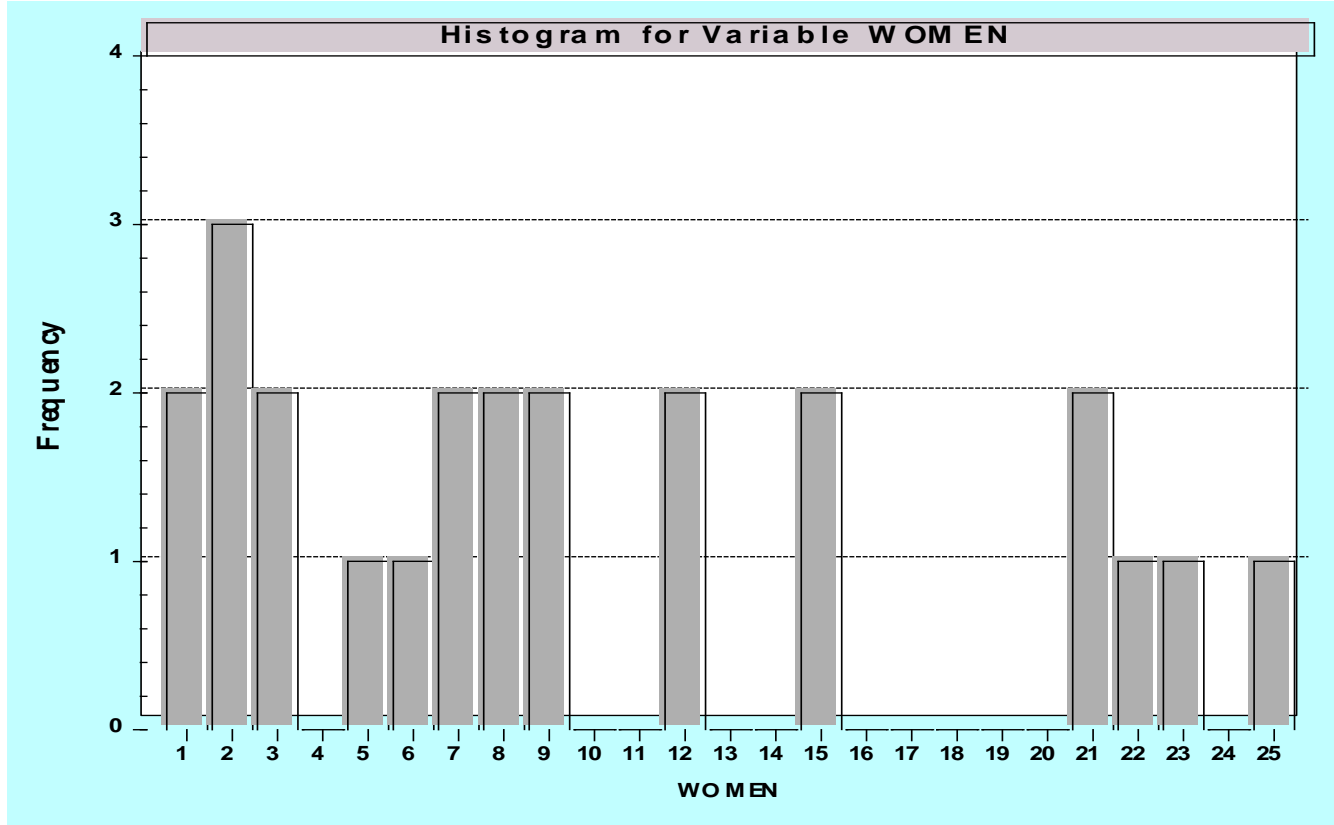

Correspondingly if there has been no female top teams over the 1990 2017 period the cumulative number of male teams varies from 1 to 28 (Figure 4). The number of these towns is $21(23 \%)$.

Figure 4. Cumulative Number of Male Teams if Female is Zero

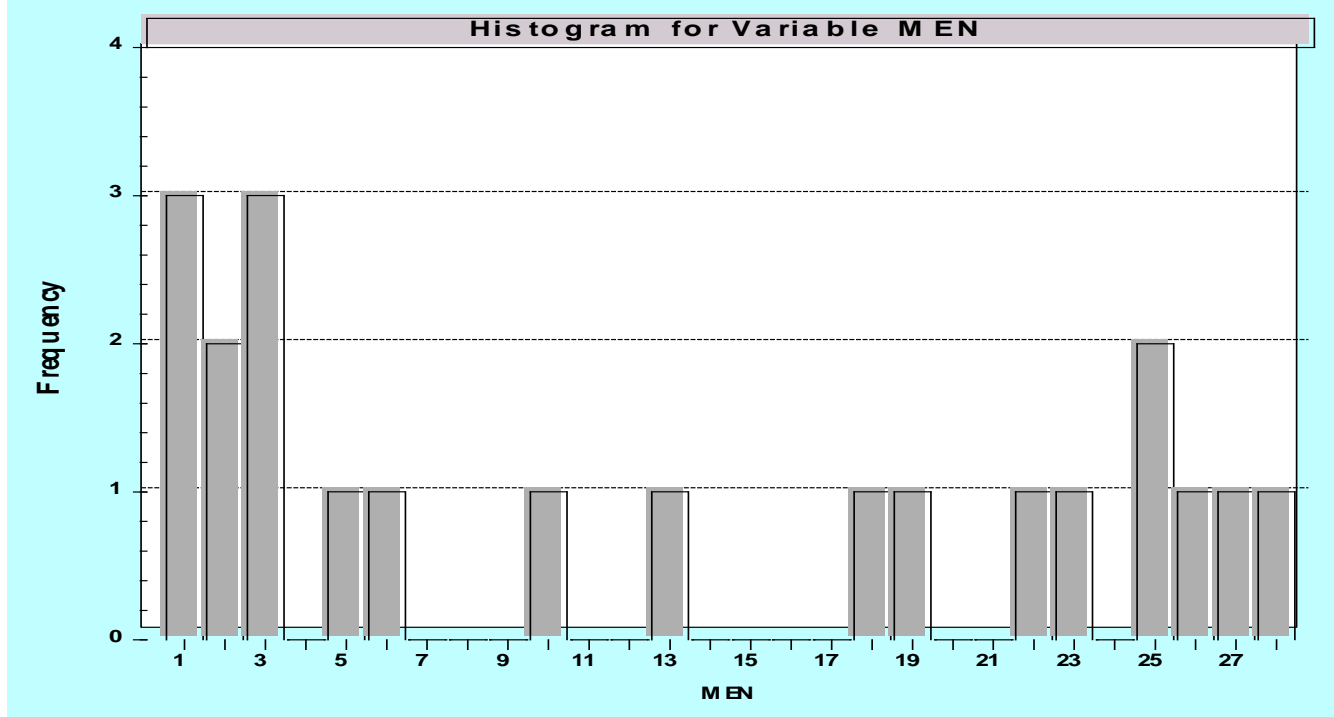


The above statistics shows that in Finland approximately $25 \%$ of towns are separated by gender: only top female or only top male teams. Rather often the towns with rather small population (less than 32000) have had a top team in volley ball but only women team or only men team.

The cumulative number of teams using Poisson and Negative Binomial regression analysis is presented below in table 5. The explaining variables are logarithms of median income of the town population and total population in 2007. Both the population and income statistics are highly autocorrelated over the period from 1990 - 2017.

Table 5. Cumulative Number of Teams Using Poisson and Negative Binomial Regression Analysis

\begin{tabular}{|c|c|c|c|c|c|c|}
\hline & Women & & Men & & Both & \\
\hline & Poisson & Neg.Bin & Poisson & Neg.Bin & Poisson & Neg.Bin \\
\hline Log INC & $\begin{array}{l}-0.717^{* *} \\
(0.226)\end{array}$ & $\begin{array}{l}-0.472 \\
(1.256)\end{array}$ & $\begin{array}{l}-3.046^{* * * *} \\
(0.220)\end{array}$ & $\begin{array}{l}-2.691^{\text {**** }} \\
(0.624)\end{array}$ & $\begin{array}{l}-1.967^{* * * * *} \\
(0.157)\end{array}$ & $\begin{array}{l}-1.623^{* *} \\
(0.609)\end{array}$ \\
\hline Log POP & $\begin{array}{l}0.992^{* * * *} \\
(0.023)\end{array}$ & $\begin{array}{l}0.778^{* * * *} \\
(0.181)\end{array}$ & $\begin{array}{l}1.100^{* * * *} \\
(0.022)\end{array}$ & $\begin{array}{l}0.748^{* * * *} \\
(0.070)\end{array}$ & $\begin{array}{l}1.049^{* * *} \\
(0.016)\end{array}$ & $\begin{array}{l}0.762^{* * *} \\
(0.069)\end{array}$ \\
\hline Constant & $\begin{array}{l}-0.511 \\
(2.151) \\
\end{array}$ & $\begin{array}{l}-0.805 \\
(11.680) \\
\end{array}$ & $\begin{array}{l}21.807^{* * * *} \\
(2.075)\end{array}$ & $\begin{array}{l}21.918^{* * * *} \\
(5.919)\end{array}$ & $\begin{array}{l}12.182^{* * * *} \\
(1.489)\end{array}$ & $\begin{array}{l}11.726^{*} \\
(5.799) \\
\end{array}$ \\
\hline$\alpha$ & & $\begin{array}{l}1.549^{* * * *} \\
(0.282)\end{array}$ & & $\begin{array}{l}0.653^{\text {*****⿲二丨匕 }} \\
(0.074)\end{array}$ & & $\begin{array}{l}0.540^{\text {**** }} \\
(0.085)\end{array}$ \\
\hline $\begin{array}{l}\text { McFadden } \\
\text { pseudo } \mathrm{R}^{2}\end{array}$ & 0.6146 & 0.497 & 0.663 & 0.482 & 0.753 & 0.489 \\
\hline $\mathrm{R}_{\text {Pearson }}^{2}$ & 0.7798 & & 0.7980 & & 0.8782 & \\
\hline $\mathrm{R}_{\text {deviance }}^{2}$ & 0.6774 & & 0.7182 & & 0.8098 & \\
\hline$\chi^{2}$ & 1068.61 & 629.75 & 1106.03 & 655.834 & 1184.49 & \\
\hline $\mathrm{G}^{2}$ & 962.35 & & 1050.36 & & 1090.62 & \\
\hline $\begin{array}{l}\text { Overdispersion: } \\
\mathrm{g}=\mu\end{array}$ & 5.719 & & 4.791 & & 4.491 & \\
\hline $\begin{array}{l}\text { Overdispersion: } \\
\mathrm{g}=\mu^{2}\end{array}$ & 1.971 & & 1.478 & & 1.982 & \\
\hline
\end{tabular}

The results in Table 5 indicate that Poisson regression which assumes that the mean equals the variance is not suitable due to overdispersion. Negative binomial regression shows that median income is significant in the case of men sports but not significant in the case of women sports. The latter has typically substantially lower spectator audience and therefore lower incomes from ticket sales. Population coefficient is positive but less than one indicating that larger towns have more top teams but the effect is diminishing.

The difference between female and male teams is next analysed. Since the difference can get both positive (more women than men teams) and negative (more men than women teams) values, a conventional regression analysis is carried out. 
Table 6. Regression Analysis: Difference between Women and Men Teams, Cumulative, Years 1990 - 2017

\begin{tabular}{|l|c|}
\hline Log INC & $47.596^{* * *}$ \\
& $(13.668)$ \\
\hline Log POP & $-8.295^{* * *}$ \\
& $(1.846)$ \\
\hline \multirow{2}{*}{ Constant } & $-395.496^{* *}$ \\
& $(128.348)$ \\
\hline $\mathrm{R}^{2}$ & 0.183 \\
\hline $\mathrm{F}$ & $11.25^{* * *}$ \\
\hline$*, * *$ and $* * *$ denote significance at $5 \%, 1 \%$ and $0.1 \%$ level.
\end{tabular}

The regression analysis result in Table 6 indicates that women team dominance is positively related to higher income towns with a small population. The theoretical model outlined proposes that a larger number of teams is related with the smaller minimum efficient scale as a fraction of market size. Conventional observations suppose that women teams have lower costs than men teams and therefore a smaller town is able to maintain more women teams.

\section{Conclusions}

The purpose of this study is to analyse the location of top teams in six different sports over a long period from 1990 to 2017. Both women and men teams are analysed. The cumulative number of top teams over this period is positively related to town size. The number of men teams is negatively related to median incomes of the inhabitants of the town or county. This is not verified with women teams. The location of women top teams is less sensitive to low incomes. A smaller town in terms of population is related to women teams. Male teams seem to require a larger town over a long period. A larger town is able to support more often male teams since the teams need a larger spectator number due to financial reasons. The number of talents is bigger in larger towns.

The variation of locations in women ice hockey is higher than in men ice hockey. The same is true with football, volleyball and baseball: more locational variation in women sports. However, the opposite is more likely in floorball and basketball. Men volleyball, basketball and baseball as well as women baseball and volleyball have been more separated in terms of location. On the contrary top level ice hockey and floorball seem to have been located in larger towns in Finland.

It is possible that the largest towns and cities in Finland seem to reduce the possibility of the neighbour towns to sustain a top level men team. This is seen in the case of Espoo and Vantaa that are the nearest cities of Helsinki which is 
the largest city in Finland. Espoo and Vantaa have had more women top teams than men teams over the long period.

\section{References}

Baimbridge M, Cameron S, Dawson P (1996) Satellite television and the demand for football: a whole new ball game? Scottish Journal of Political Economy 43(3): 317333.

Borland J, Lye J (1992) Attendance at Australian Rules football: A panel study. Applied Economics 24(9): 1053-1058.

Coates D, Harrison T (2005) Baseball strikes and the demand for attendance. Journal of Sports Economics 6(3): 282-302.

Coates D, Humphreys BR (2007) Ticket prices, concessions and attendance at professional sporting events. International Journal of Sport Finance 2(3): 161-170.

Coates D, Humphreys BR (1999) The growth effects of sport franchises, stadia, and arenas. Journal of Policy Analysis and Management 18(4): 601-624.

Depken CA (2001) Fan loyalty in professional sports. Journal of Sports Economics 2(3): 275-284.

Downward P, Rasciute S (2010) The relative demands for sports and leisure in England. European Sport management Quarterly: ESMQ 10(2): 189-214.

Falter J-M, Perignon C (2000) Demand for football and intramatch winning probability: an essay on the glorious uncertainty of sports. (statistical data included). Applied Economics 32(13): 1757.

Hartmann-Tews I (2006) Social stratification in sport and sport policy in the European Union. European Journal for Sport and Society 3(2): 109-124.

Hofstede G (1980) Motivation, leadership, and organization: Do American theories apply abroad? Organizational Dynamics 9(1): 42-63.

Itkonen H, Nevala A (1998) Urheilumenestyksen paikantuminen - esimerkkinä Joensuu. [The localisation of sport success]. In P. Tuunainen ed., Pohjois-Karjalan historiallinen yhdistys.Elämää entisajan Joensuussa. Joensuun kaupunki 1848-1998. Pohjois-Karjalan historiallisen yhdistyksen vuosikirja 6, 335-343.

Jones JCH, Ferguson DG (1988) Location and survival in the National Hockey League. The Journal of Industrial Economics 36(4): 443-457.

Martin S (1993) Advanced Industrial Economics, 1st ed. Oxford, UK: Basil Blackwell.

Oberhofer H, Philippovich T, Winner H (2015) Firm survival in professional sports, Journal of Sports Economics 16(1): 59-85.

Quirk J, El Hodiri M (1974) The economic theory of a sports league. In R Noll (ed) Government and the Sports Business, 33-80. Washington, DC: Brookings.

Ross SF, Szymanski S (2002) Open competition in league sports, 625. Wisconsin Law Review.

Siegfried J, Zimbalist A (2006) The economic impact of sports facilities, teams and mega-events. Australian Economic Review 39(4): 420-427.

Siegfried J, Zimbalist A (2000) The economics of sports facilities and their communities. Journal of Economic Perspectives 14(3): 95-114.

Suominen S (2017) The Geography of sport in Finland. Athens Journal of Sport 4(2): 107-121.

Thibaut E, Eakins J, Vos S, Scheerder J (2017) Time and money expenditure in sports participation: The role of income in consuming the most practiced sports activities in Flanders. Sport Management Review 20(5): 455-467. 
